\title{
Effects of guar gum on plasma urea, insulin and glucose in the growing pig
}

\author{
BY KJELL MALMLÖF ${ }^{1}$, CARLOS SIMOES NUNES ${ }^{2}$ \\ AND STEFAN ASKBRANT \\ 1 Department of Animal Nutrition and Management, Swedish University of Agricultural \\ Sciences, S-750 07 Uppsala, Sweden \\ ${ }^{2}$ INRA, Laboratoire de Physiologie de la Nutrition, Centre National de Recherches \\ Zootechniques, 78350 Jouy-en-Josas, France
}

(Received 17 September 1987 - Accepted 9 September 1988)

\begin{abstract}
1. Six growing pigs fitted with portal and arterial blood cannulas were given a barley-fishmeal diet, either alone or supplemented with guar gum at $60 \mathrm{~g} / \mathrm{kg}$ basal diet. Blood samples were taken during $8 \mathrm{~h}$ following test meals given at 08.00 hours.

2. Ingestion of the guar-gum-supplemented diet appeared to increase systematically portal and arterial levels of plasma urea. At peak values, 4 and $5 \mathrm{~h}$ after the test meal, this effect was statistically significant $(P<0.05)$.

3. Irrespective of which diet was given, portal and arterial blood samples, withdrawn at the same time, were found to have about the same concentration of urea. This was found throughout the $8 \mathrm{~h}$ studied and implies that no net exchange of urea between the circulation and the gastrointestinal tract, as a whole, took place.

4. In the time-period $30-60 \mathrm{~min}$ following the test meal, guar gum significantly reduced the postprandial hyperglycaemia and hyperinsulinaemia in portal blood.
\end{abstract}

In human beings and pigs, ingestion of the viscous polysaccharide guar gum, together with meals or oral glucose loads, has been shown to reduce postprandial blood concentrations of glucose and insulin (Jenkins et al. 1977, 1978; Morgan et al. 1979; Rainbird et al. 1984; Sambrook \& Rainbird, 1985). Since insulin, in addition to mediating glucose transport, exerts several anabolic functions (for review, see Kahn et al. 1981), a reduction in circulating insulin following meals might, therefore, reduce protein synthesis. In consequence, growth may be retarded (Romsos et al. 1971), and plasma urea levels increased (Fuller $e_{\hat{\imath}}$ al. 1977).

The main aim of the present study was to examine whether guar gum, in addition to reducing postprandial hyperglycaemia and hyperinsulinaemia, also alters the dynamics of plasma urea. At the start of the study the uncertainty as to the effects of dietary fibre on exchange of urea between the gastrointestinal tract and the circulation was considerable. In view of this fact, it was considered useful to measure plasma urea in both arterial and portal blood.

\section{MATERIALS AND METHODS}

The effects of guar gum on portal and arterial plasma levels of urea, $\alpha$-amino-nitrogen, glucose and insulin (immunoreactive insulin) were studied in six female Swedish Landrace $\times$ Yorkshire pigs $(35-50 \mathrm{~kg}$ ). The guar-gum diet was formulated by adding $60 \mathrm{~g}$ guar gum powder (Meyprofin 500; Meyhall Chemical AG, Kreutzlingen, Switzerland)/kg basal diet. According to the supplier, a $10 \mathrm{~g} / 1$ solution of Meyprofin 500, allowed to stand for $2 \mathrm{~h}$, has a viscosity of $4800 \mathrm{mPa} / \mathrm{s}$ (Brookfield RVT, $20 \mathrm{rev} / \mathrm{min}, 25^{\circ}$ ). The crude protein $(\mathrm{N} \times 6.25)$ content of the guar gum powder was $36 \mathrm{~g} / \mathrm{kg}$ and those of the basal and guar-gum diets 171 and $164 \mathrm{~g} / \mathrm{kg}$ respectively. The basal diet contained $840 \mathrm{~g}$ barley, 
$120 \mathrm{~g}$ fishmeal and $40 \mathrm{~g}$ minerals and vitamins $/ \mathrm{kg}$. The diets were given as an air-dry meal and in isonitrogenous amounts. Daily rations provided the animals with $15.3 \mathrm{~g}$ crude protein $/ \mathrm{kg}$ metabolic weight $\left(\mathrm{W}^{0.75}\right)$. Thus, $89 \mathrm{~g}$ basal diet and $93 \mathrm{~g}$ guar gum diet were supplied per $\mathrm{kg} \mathrm{W}^{0.75}$. Water was supplied ad lib.

\section{Surgery}

The animals were fitted with permanent blood cannulas introduced into the portal vein and the brachio-cephalic artery, essentially as described by Rérat et al. (1980). The anaesthetic procedures and catheterization were as described by Malmlöf (1987).

\section{Experimental procedures}

The experiment was performed according to a crossover design. After surgery the animals were placed in individual cages and were back on full feed within 3-4 d. Three animals were given the basal diet and three the guar-gum diet. Meals were given at 08.00 and 16.00 hours, and lighting was provided between 07.00 and 19.00 hours. At 7-8 d after surgery, one series of portal and arterial blood samples was obtained from each animal. On the following day, animals which had received the basal diet were switched to the guar-gum diet and vice versa. After this change of diet a time-period of $5 \mathrm{~d}$ elapsed before another series of blood samples was taken. Blood samples were withdrawn during an $8 \mathrm{~h}$ period following the 08.00 hour meal. During the first $2 \mathrm{~h}$ samples were taken every $30 \mathrm{~min}$, thereafter hourly. Blood was directly transferred into heparinized tubes and centrifuged; the plasma was decanted and frozen $\left(-20^{\circ}\right)$ until analysed.

\section{Analyses}

The plasma concentrations of glucose, urea and amino acids $(\alpha$-amino- $N)$ were analysed using a Technicon AutoAnalyzer II C, glucose by a glucose oxidase $(E C 1 \cdot 1 \cdot 3 \cdot 4)$ method (Glox ${ }^{\mathbb{B}}$; Kabi Diagnostica, Stockholm, Sweden), and urea and $\alpha$-amino-N according to Technicon methods (Technicon Instruments Co., 1972; Technicon Scandinavia AB, 1979). The concentration of immunoreactive insulin in plasma was measured essentially as described by Herbert et al. (1965). However, ${ }^{125} \mathrm{I}$-labelled insulin was used as the tracer (Phadesph ${ }^{\circledR}$, Pharmacia Diagnostics AB, Uppsala, Sweden) and the antibody-antigen mixture was incubated for $16 \mathrm{~h}$ at $4^{\circ}$. A purified porcine insulin was used as standard (Novo Research Institute, Bagsvaerd, Denmark). The crude protein content of diets was analysed according to the conventional macro-Kjeldahl procedure.

\section{Calculations and statistics}

The differences between the portal and arterial plasma concentrations (porto-arterial differences) were calculated individually for each animal and time of sampling. Means ( $n$ 6) of these calculated porto-arterial differences and of the underlying portal and arterial plasma levels are presented graphically. For reasons of clarity standard errors of these means were impossible to include in some of the values and were therefore generally omitted. Tests of potential differences between the two treatments were performed by $t$ tests for paired observations (SAS Institute Inc., 1985), at two separate time points on the curves. For glucose, $\alpha$-amino-N and insulin this was done at 08.30 and 09.00 hours and for urea at 12.00 and 13.00 hours. The order in which the diets were given had no specific effect on the results (Malmlöf, 1987). 


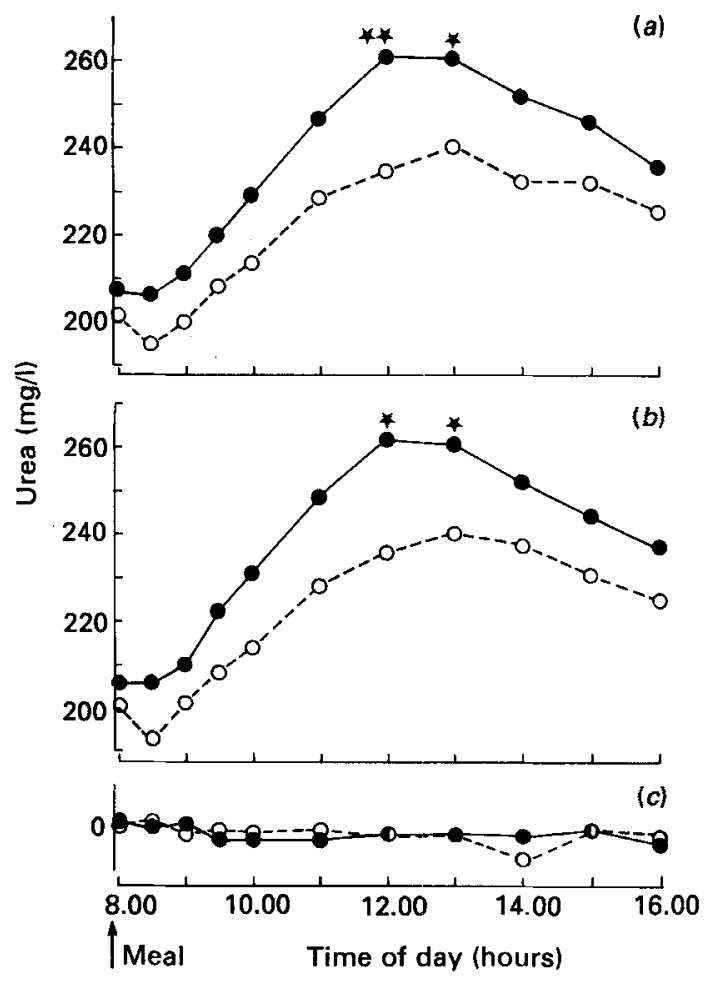

Fig. 1. Changes in $(a)$ portal and $(b)$ arterial plasma urea concentrations in pigs fed on a basal diet alone $(O)$ or the same diet supplemented with guar gum $(O) ;(c)$ the difference between portal and arterial concentrations. Results are expressed as means of six observations and significant differences from the basal diet are indicated: ${ }^{*} P<0.05,{ }^{* *} P<0.01$.

\section{RESULTS \\ Urea}

Additions of guar gum to the diet appeared to induce a systematic increase in both portal and arterial plasma urea levels throughout the time-period studied (Fig. 1). When tested at peak values, 4 and $5 \mathrm{~h}$ after ingestion of the meal, this effect was found to be statistically significant. The plasma urea concentrations in portal and arterial blood withdrawn at the same time were found to be very similar. This was found with both diets and resulted in porto-arterial differences of plasma urea which, at all times studied, were close to zero (Fig. 1).

\section{Glucose}

The addition of guar gum to the basal diet produced a decrease in the portal plasma concentrations of glucose at 30 and $60 \mathrm{~min}$ after the meal (Fig. 2). Furthermore, at $60 \mathrm{~min}$ after feeding, the porto-arterial differences in plasma glucose were also decreased by the guar gum addition, whereas arterial plasma glucose levels were not affected (Fig. 2).

$$
\alpha \text {-Amino- } N
$$

The guar-gum diet reduced the concentration of $\alpha$-amino- $\mathrm{N}$ in both portal and arterial blood plasma at $60 \mathrm{~min}$ after the meal (Fig. 3). However, this diet did not affect the 


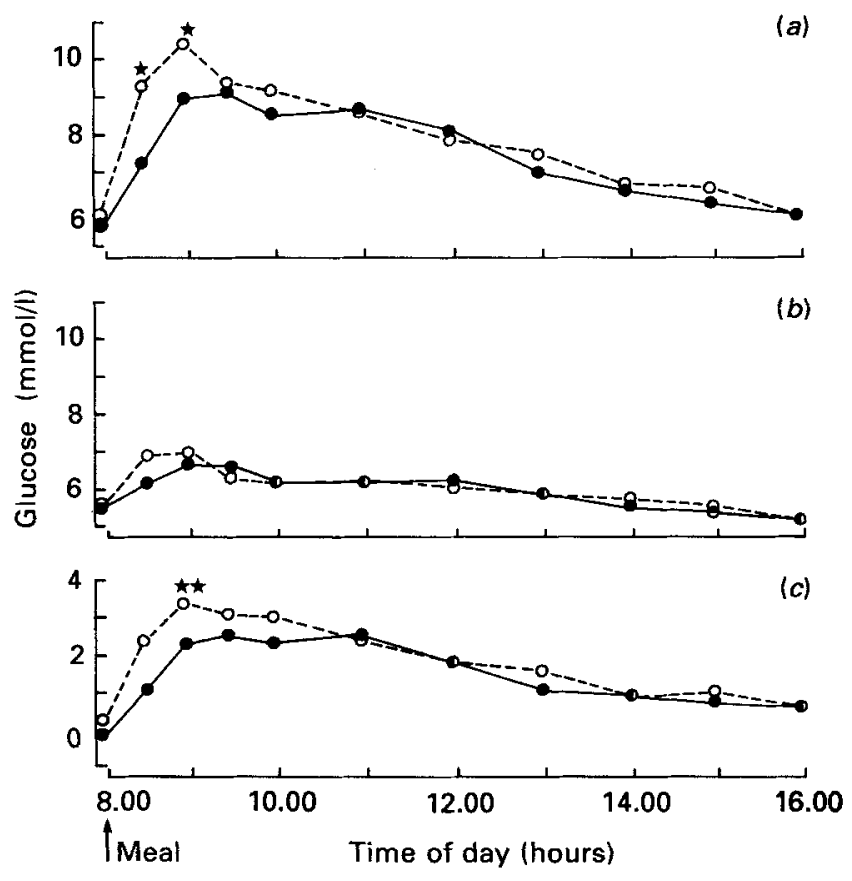

Fig. 2. Changes in (a) portal and $(b)$ arterial plasma glucose concentrations in pigs fed on a basal diet alone $(O)$ or the same diet supplemented with guar gum $(\mathbf{O}) ;(c)$ the difference between portal and arterial concentrations. Results are expressed as means of six observations and significant differences from the basal diet are indicated: ${ }^{*} P<0.05,{ }^{* *} P<0.01$.

porto-arterial concentration difference in plasma $\alpha$-amino- $\mathrm{N}$ in comparison with the unsupplemented diet.

\section{Insulin}

At 30 and $60 \mathrm{~min}$ after the test meal, the guar-gum diet appeared to decrease portal and arterial plasma insulin levels, and even the porto-arterial insulin differences (Fig. 4). However, this could not be statistically verified if the two time-points were analysed separately. If, instead, mean values ( $n$ 6) were calculated over both time-points for each animal within treatment, the subsequent $t$ test for paired samples showed that the average effect of guar gum during the time-period in question was to decrease significantly $(P<0.05)$ portal and arterial insulin levels. The tendency for a decrease in the portoarterial differences of plasma insulin during the same time was, however, not statistically significant.

\section{DISCUSSION}

In the present study it was found that supplements of guar gum to a basal diet significantly increased plasma urea levels. It was also found that the concentration of plasma urea in portal blood was at all times equal to the plasma urea concentration found in the arterial blood, regardless of which diet was given. Thus, neither diet induced a significant net flux of urea from the gut into the circulation or vice versa. Similar results have been obtained 


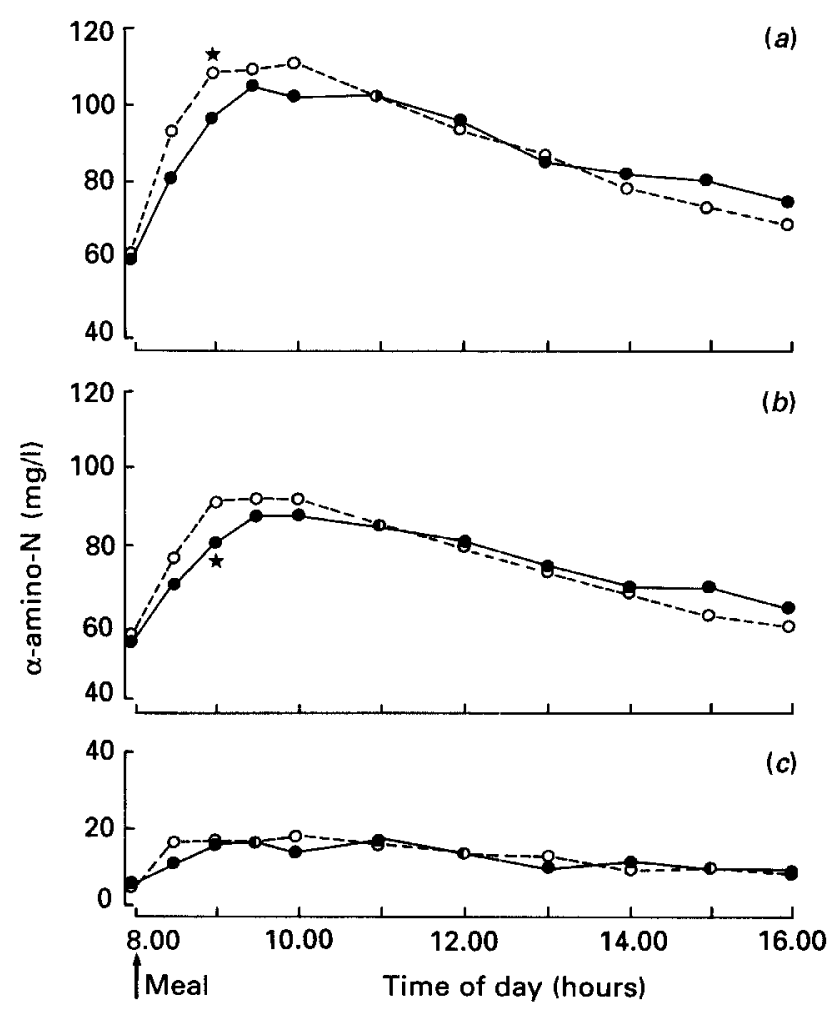

Fig. 3. Changes in (a) portal and $(b)$ arterial plasma $\alpha$-amino-nitrogen concentrations in pigs fed on a basal diet alone $(O)$ or the same diet supplemented with guar gum $(\boldsymbol{O}) ;(c)$ the difference between portal and arterial concentrations. Results are expressed as means of six observations and significant differences from the basal diet are indicated: $* P<0.05$.

with wheat-straw-supplemented diets (Malmlöf, 1987). In a study by Low \& Rainbird (1984) it was observed that guar gum increased the secretion of $\mathrm{N}$ in isolated loops of the small intestine. The present study suggests that urea might have contributed little to this increase.

Guar gum is known to reduce postprandial hyperglycaemia and hyperinsulinaemia in man and pigs (Jenkins et al. 1977, 1978; Morgan et al. 1979; Sambrook \& Rainbird, 1985). In the present study, these effects were particularly pronounced in the samples withdrawn from the portal vein at 30 and $60 \mathrm{~min}$, and probably resulted from a guar-gum-mediated reduction in the rate of glucose absorption (Rainbird et al. 1984). However, a similar effect on the absorption of amino acids could not be confirmed in the present study. If guar gum significantly influences the absorption of amino acids, then a specific effect on the porto-arterial difference of plasma $\alpha$-amino- $\mathrm{N}$ would be expected, unless mucosal amino acid metabolism or blood flow are dramatically changed. Although guar gum decreased both portal and arterial levels of $\alpha$-amino- $\mathrm{N}$ at $1 \mathrm{~h}$ following the meal, the difference in concentrations remained unchanged. Thus, the amino acid enrichment of blood traversing the gastrointestinal tract appears to have been unaffected.

In conclusion, the present work has shown that guar gum, in addition to reducing 


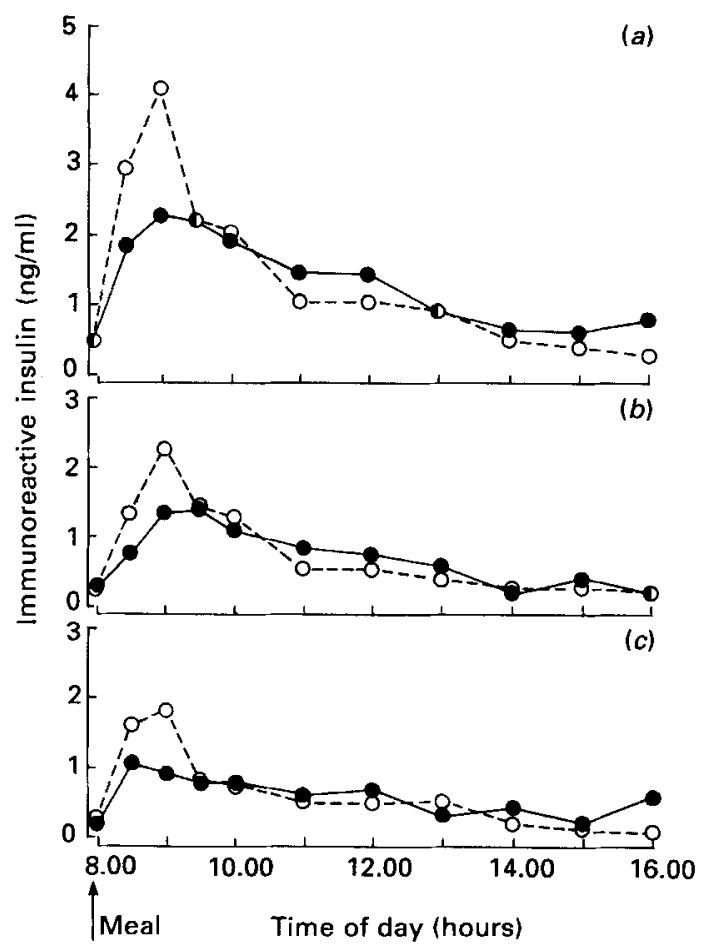

Fig. 4. Changes in (a) portal and $(b)$ arterial plasma concentrations of immunoreactive insulin in pigs fed on a basal diet alone $(O)$ or the same diet supplemented with guar gum $(O) ;(c)$ the difference between portal and arterial concentrations. Results are expressed as means of six observations.

postprandial hyperglycaemia and hyperinsulinaemia, also increased plasma urea levels. At present an interrelation between these changes cannot be excluded (Fuller et al. 1977), a fact that hopefully will stimulate more research in this area.

The authors wish to acknowledge the valuable linguistic advice given by Dr Hadden Graham, and the Swedish Council for Forestry and Agricultural Research for financing the present study by a grant, 552/83 D4:3.

\section{REFERENCES}

Fuller, M., Weekes, T., Cadenhead, A. \& Bruce, J. (1977). The protein-sparing effect of carbohydrate: the role of insulin. British Journal of Nutrition 38, 489-496.

Herbert, V., Lau, K., Gottlieb, C. \& Bleicher, S. (1965). Coated charcoal immunoassay of insulin. Journal of Clinical Endocrinology and Metabolism 25, 1375-1384.

Jenkins, D., Leeds, A., Gassull, M., Cochet, B. \& Alberti, G. (1977). Decrease in postprandial insulin and glucose concentrations by guar and pectin. Annals of Internal Medicine 86, 20-23.

Jenkins, D., Wolever, T., Leeds, A., Gassull, M., Haisman, P., Dilawari, J., Goff, D., Metz, G. \& Alberti, G. (1978). Dietary fibres, fibre analogues, and glucose tolerance: importance of viscosity. British Medical Journal i, 1392-1394.

Kahn, R., Baird, K., Flier, J., Grunfeld, C., Harmon, J., Harrison, L., Karlsson, A., Kasuga, M., King, G., Lang, U., Podskalny, J. \& Obberghen, E. (1981). Insulin receptors, receptor antibodies and the mechanisms of insulin action. Recent Progress in Hormone Research 37, 477-533.

Low, A. G. \& Rainbird, A. L. (1984). Effect of guar gum on nitrogen secretion into isolated loops of jejunum in conscious growing pigs. British Journal of Nutrition 52, 499-505. 
Malmlöf, K. (1987). Porto-arterial plasma concentration differences of urea and ammonia-nitrogen in growing pigs given high- and low-fibre diets. British Journal of Nutrition 57, 439-446.

Morgan, L., Goulder, T., Tsiolakis, D., Marks, V. \& Alberti, K. G. M. M. (1979). The effect of unabsorbable carbohydrate on gut hormones. Diabetologia 17, 85-89.

Rainbird, A. L., Low, A. G. \& Zebrowska, T. (1984). Effect of guar gum on glucose and water absorption from isolated loops of jejunum in conscious growing pigs. British Journal of Nutrition 52, 489-498.

Rérat, A., Vaugelade, P. \& Villiers, P. (1980). A new method for measuring the absorption of nutrients in the pig: critical examination. In Current Concepts of Digestion and Absorption in Pigs, pp. 177-214 [A. G. Low and I. G. Partridge, editors]. Reading: National Institute for Research in Dairying.

Romsos, D., Leveille, G. \& Allee, G. (1971). Alloxan diabetes in the pig (Sus domesticus). Response to glucose, tolbutamide and insulin administration. Comparative Biochemistry and Physiology 40 A, 557-568.

Sambrook, I. E. \& Rainbird, A. L. (1985). The effect of guar gum and level and source of dietary fat and glucose tolerance in growing pigs. British Journal of Nutrition 54, 27-35.

SAS Institute Inc. (1985). SAS User's Guide, Statistics, 5th ed. Cary, NC: SAS Institute Inc.

Technicon Instruments Co. (1972). Clinical Method no. 01. Tarrytown, New York: Technicon Instruments Co.

Technicon Scandinavia AB (1979). Method no. 78-5R. Stockholm: Technicon Scandinavia AB. 